\title{
Designing with risk
}

\author{
J Venter Julian Venter Consulting, Australia
}

\begin{abstract}
The purpose of this paper is to open the debate around geotechnical design methodology for open pits and to present a case for proper planning of design work in order to improve the value of open pit designs. The approach taken consisted of reviewing the literature on design methodology and demonstrating, through an open pit example, that designing can be carried out using a risk assessment based approach. Through the example, a risk based design evaluation tool is developed that documents and summarises a whole design on a single page. The risk based design evaluation tool is proposed for use by design project managers, designers, design documenters, reviewers and design users to improve design rigour through visual demonstration of Bieniawski's design principles, better communication and more objective review. The paper also presents a site investigation geology summary tool to help document failure mechanisms to be used as input for the design analysis.
\end{abstract}

\section{Introduction}

The aim of this paper is to again bring to the fore the topic of design and how one can improve the value added by geotechnical slope design. This is a particularly relevant topic as most value is created or destroyed before a project is implemented as demonstrated by Mackenzie and Cusworth (2007) in their paper evaluating feasibility studies (see Figure 1). This principle is valid on two levels: firstly, poor design limits mining project value, as shown by Figure 1, but good execution can, at best, maintain value already created; secondly, if one considers the activity of design as opposed to mining, the scoping to feasibility stages in Figure 1 represents design planning while the execution stage represents design. It is clear that planning a design adds more value to a design than carrying out a design. In short, good planning adds value but good execution can only maintain value. Poor planning limits value, but good execution cannot increase value already destroyed by poor planning.

Impact of study phases on project value

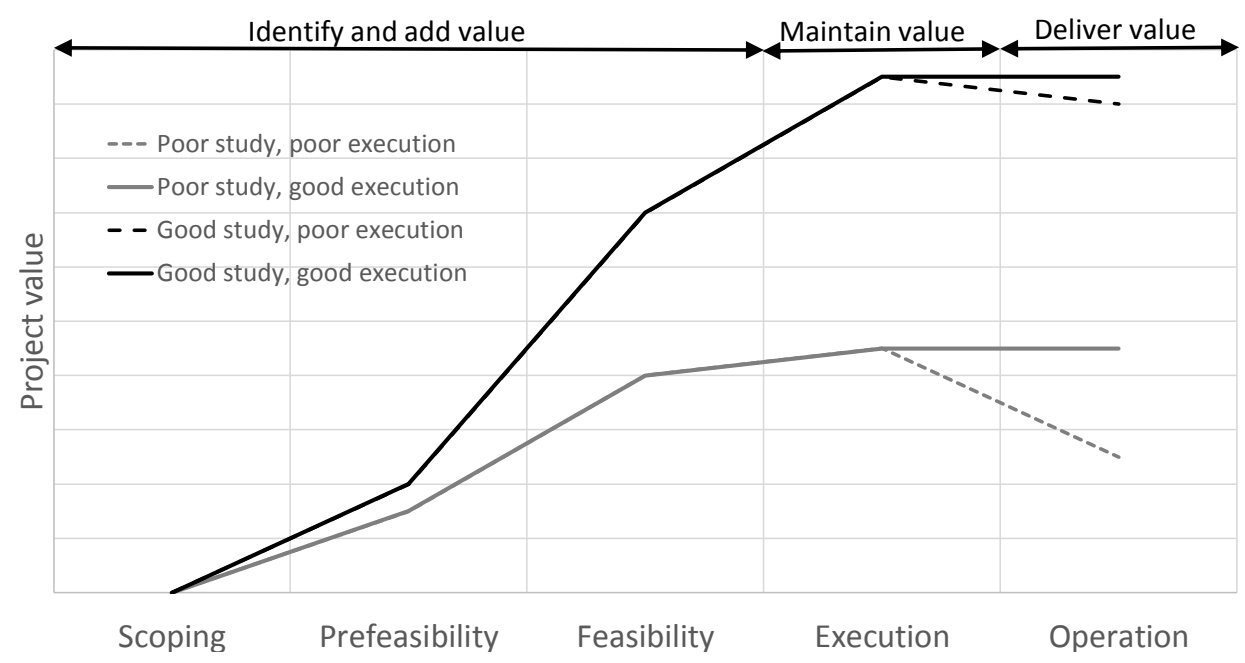

Figure 1 Value creation after Mackenzie and Cusworth (2007)

The last few decades have seen an increasing number of publications on the topic of risk based design in geotechnical engineering. These publications have covered a range of topics, for example, carrying out calculations to estimate risk such as: Ang and Tang (1975, 1990, 2007); Baecher and Christian (2003); Fenton 
and Griffiths (2008); and Harr (1987) to name but a few. Some publications also include understanding and defining acceptable risk such as Baecher and Christian (2003); or obtaining input parameters for risk based design such as Harr (1987); and how to interpret risk and probability such as Vick (2002). Most of the publications, however, still deal with design analysis, and not design itself. In other words, the focus has been on 'how to do the calculations', not 'which calculations to do and what to do with the answers'. This has left many experienced geotechnical engineers and engineering geologists feeling that risk based design is simply a passing fashion that the younger generation of engineers will eventually grow out of, preferably sooner rather than later.

The guidance provided to date on 'which calculations to do' focuses mainly around the work presented by Bieniawski $(1984,1988,1992)$ with an alternative interpretation by Stacey (2014). A contribution was also made by Hudson and Harrison (1997) through their Interaction Matrices concept. Finally, the Large Open Pit Project (eds Read \& Stacey 2009) provided a diagram outlining the design process.

Altogether a significant amount of progress has been made, however, much of the literature still appears on face value to be unrelated and possibly without practical application. This paper aims to fill in some of the gaps between design, site investigation and design analysis by investigating risk based geotechnical design from a bigger picture or strategic point of view. The investigation starts by analysing the anatomy of design in geotechnical engineering based on the systems presented by the aforementioned authors. A risk based design evaluation tool, or the 'design evaluation tool', is then developed to simplify the application of a sound design process (see Section 4 for more details). The design evaluation tool can be used to help plan a design at strategic and tactical level and can also aid in the supervision, documentation, communication and review of a design. In contrast to previous design systems that focussed on strategy (Bieniawski 1992) and activities (eds Read \& Stacey 2009), the design evaluation tool is based on the flow of information through a design and contains elements of both activities and deliverables.

\section{$2 \quad$ Anatomy of design}

There are likely as many definitions for the act of designing as there are practitioners who design. Naturally a more specific definition is required for open pit slopes. Such a definition is offered by ABET (1987): "Engineering design is the process of devising a system, component, or process to meet desired needs." Another definition, more specific to slope engineering, is offered by Stacey (2009): "The aim of any open pit mine design is to provide an optimal excavation configuration in the context of safety, ore recovery and final return". To achieve these goals consistently it is advisable to use a systematic approach to maximise the chances of success. Such a systematic approach should contain all the essential elements of a good design. This section starts by presenting the design processes, followed by an analysis of how a design can fail and the essential elements of a good design.

\section{$2.1 \quad$ Design processes}

Bieniawski (1992) presented a design process that, if followed, promises to improve design practice. Bieniawski (1992) described the higher level design process but did not establish a direct link with the actual work required. Independently, Hudson and Harrison (1997) recognised that a more detailed understanding of the factors involved in design is required and produced an interaction matrix, which helps with the design analysis but seemingly has no direct link with the design process as presented by Bieniawski (1992). If one considers the definition of design as presented by Stacey (2009) or ABET (1987) it is clear that a design must meet a list of requirements and indeed Bieniawski (1992) stated as his Design Principle 1 that there must be clarity of design objectives and functional requirements. This creates an incentive to create a checklist of requirements to be satisfied. It is this requirement to measure a design against design objectives and the incentive for a checklist that opens the door for a risk assessment based design process. In this context, risk is interpreted as the risk of not meeting the design objectives, which is a much wider definition than just safety risk. This has a far reaching effect as without comparison against design objectives, a designer cannot 
prove that their design will meet the stated objectives. Indeed, the Limit States design concept (Baecher \& Christian 2003), as used in civil engineering, is basically a comparison against desired design objectives.

\subsection{When does a design fail to meet the desired objectives?}

Before defining what information is needed for a design, it is first necessary to define what a design is and, in particular, how a design can fail to meet its desired objectives. A design is not an open pit or other physical object. A design is a document on paper or digital files with supporting drawings and models that communicates not only how an open pit should look but also what information was considered when deciding what shape an open pit should assume. A perfect design is not only one that is clearly communicated but also one that considered all the possible scenarios that could occur in the life of the open pit or prototype, and showed which ones met the desired objectives and which ones do not. Such information is of great value to the miner or asset owner as it allows them to make correct and timely business decisions during mining excavation. This naturally implies that a poor design is one where sufficient scenarios were not considered and the design is not well supported and communicated, i.e. a design that does not allow the prototype slope to meet its stated objectives during its service life without unplanned additional work. Given the amount of work required to prepare a perfect design, it is clear that a mining company or asset owner is also accountable for the designs they commission as they provide not only the guidance but also the financial resources for a design. This is not to say that all questions are to be answered up front but that the level of design resources is indirectly proportionate to risk. Open pit owners willing to accept more risk can spend less on design and open pit owners with lower risk appetites need to spend more on design. There are, of course, limits to what information can be gained upfront and strategies are available that allow continuous data collection during mining.

\section{Design evaluation tool development}

This section develops the concepts for the design evaluation tool by applying the concepts behind the tool to an example. The example used to develop the design evaluation tool comprises a typical open pit presented as Figure 2. The first step in designing a slope is to determine the design objectives, functional requirements, performance objectives, design constraints and open pit or prototype constraints as without these it would not be possible to create a design that meets the owner's requirements.

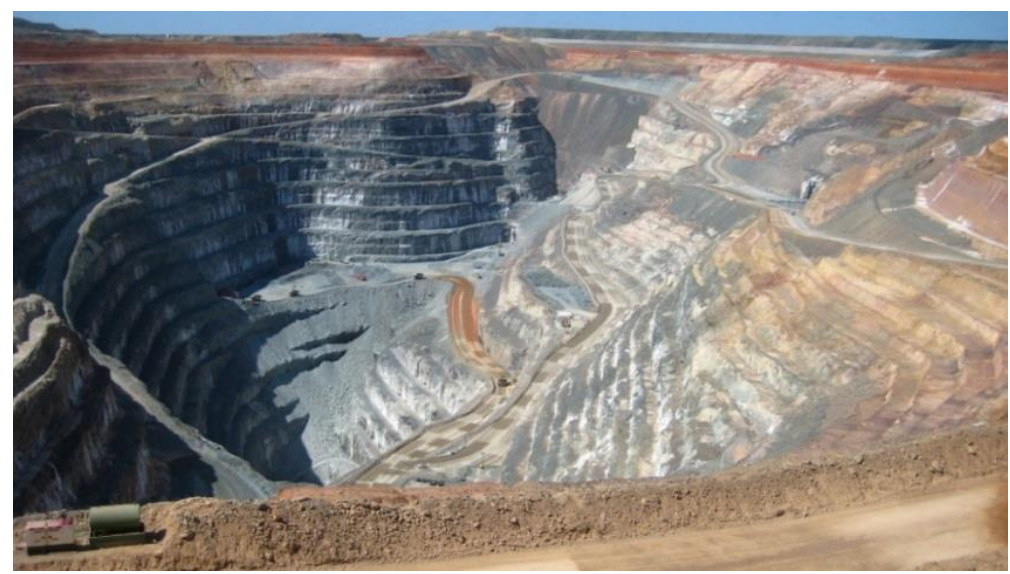

Figure 2 Open pit example (Sunrise Dam, Australia after Wikipedia (2016))

The second step in designing the example slope is to identify the components. Components comprise the identifiable parts of the whole. In the case of an open pit one might consider the overall slope, inter-ramp slope, batter slope, ramp width, berm width and geotechnical berm width to be the components. Given the geometry of this system there will be some natural overlap between components. One can, however, also argue that different slope sectors behave differently with the result that each slope sector will have each of the aforementioned components. In this way, the open pit presented as Figure 2 will have possibly seven design sectors and six components for each design sector. Added together, this results in 42 components to be designed. In reality there may be similarities between components and the analysis for these can be 
combined. For instance, the geology could be such that the batter slopes may all be analysed as if they are the same component regardless of design sector. A prudent designer will identify such similarities based on geology and other factors and use them to simplify the design.

The next step in the example design is to decide what load cases or scenarios each component should be able to survive. Guidance for this decision is often provided by governmental agencies, especially where public access is allowed, but in mining these decisions require guidance from the mining companies or insurance companies. For example, the owners of the example pit may require the open pit to meet performance objectives for several load cases or scenarios such as: normal operating conditions, a cyclone, a 1:50 year flood, a magnitude 6 earthquake, an adverse fault, dewatering pump failure and poor blasting. Note that some of these scenarios are man-made, such as poor blasting, some are natural occurrences of short duration, such as earthquakes, and some stem from uncertainty in knowledge, such as the testing of a geological scenario where an adverse fault is considered. Note that at this stage the wording 'performance objectives' is used, not 'acceptance criteria'. The topic of acceptance criteria can only be addressed once the modelling methodology has been decided on. It is often considered acceptable to relax the performance objectives for short-duration unlikely events as compared to long-term normal operating conditions. As is the case for components, economies may be found as similar load cases/scenarios can be defined for many components, thereby eliminating the need to analyse hundreds or thousands of scenarios. In the case of the example slope, all but one of the scenarios are valid for all components.

The consequences to the example slope of component failure for each of the load cases/scenarios can now be defined. There can be more than one consequence for each load case/scenario. For instance, overall scale slope instability resulting from the 1 in 50 year flood scenario may result in safety consequences and economic loss. As there will be differences in controls and exposure to these consequences, the designer needs to define these early on in the design process.

Exposure to each scenario-consequence combination for the open pit can be defined next. Using the above example, the exposure to economic loss resulting from a 1 in 50 year flood scenario may be 1 in 50 or 2 per cent as infrastructure and orebodies cannot be moved easily but the exposure to personnel safety may only be 1 per cent, if daylight mining only is considered. In reality, monitoring controls may reduce effective exposure to personnel even further but may not change the expectation of economic loss by a significant amount.

Sufficient information is now available to consider the hazards. According to AS/NZS 4360 (AS/NZS 4360 1999) a hazard is: "a source of potential harm or a situation with a potential to cause loss". In the case of open pit slopes, hazards may be batter scale instability, overall scale instability, erosion, rockfall or displacement of infrastructure at the crest and many others. Hazards are not to be confused with failure mechanisms, which are discussed next.

For a hazard to mobilise, failure mechanisms are required. Overall scale slope instability, as a hazard, can be caused by rock mass shear failure, structurally controlled failure, Step-Path failure, and many more. Rockfall as a hazard can be caused by erosion, wind, water, or many other factors. It is tempting at this point to introduce triggers, such as rainfall, but these were already considered as load cases/scenarios. In conclusion, each hazard can have multiple failure mechanisms.

Only at this point can design models be considered. A design model is an understanding of what the failure mechanism looks like for a given hazard, consequence, scenario and component. Many geotechnical models are design models. For a design model to be complete all information required for analysis must be defined. This sounds like a lot of work but, once again, economies are usually found and designs often have only a few different design models.

The next step is to decide on one or more analysis methods. The type of analysis method, rigour, complexity and number of analysis methods used, can be determined based on the budget available, the consequence of failure for a scenario and the level of design confidence required. 
The acceptance criteria are only selected once the design analysis methods have been decided on. The reason being that different analysis methods provide different results that cannot always be compared.

For example, Limit Equilibrium methods provide Factor of Safety but comparison with the strength reduction factor, as applied using finite element analysis or finite difference methods, often result in differences. A rigid specification of Factor of Safety cannot, therefore, be defined before selecting analysis methods. In addition, should acceptance criteria in terms of displacement be required, even more differences can result. Acceptance criteria are, therefore, method dependent, however, should be selected with the desired functional requirements and acceptable risk levels in mind.

Selecting final parameters for design purposes requires an understanding of the importance of each parameter in terms of the desired acceptance criteria for the life of the scenario. Interaction analysis is a design step where each input parameter is varied over its possible range and the change in the model output recorded. Comparing the variation in model output will quickly establish which parameters are worth further investigation and which parameters can be selected through simple assumptions. Understanding such sensitivities is the key to selecting the most appropriate design input parameters. It is important to note here, though, that some parameters are model dependent, such as finite element grid size or the distance to the nearest external boundary. Sensitivities for such model parameters also need to be understood as they may distort model outcomes by a greater margin than incorrect geotechnical parameters.

Finally, after selection of the design input parameters, whether as single representative values or distributions, the analysis can be carried out as per the design table.

On completion of the design analysis, the resulting performance indicators, such as Factor of Safety or Probability of Failure, can be quantified and compared to the acceptance criteria. For cases where the acceptance criteria are not met, iterative analysis can be carried out to adjust the design until the criteria are met.

In many cases there will be multiple controls to choose from. In general, these controls will range from design changes that will be costly but require little monitoring or maintenance, to controls that are less costly up front but delay critical decision-making for later and may have significant monitoring and maintenance requirements. These strategies are implementation strategies and need to be defined for a design. In some cases, multiple such strategies are recommended and an asset owner is allowed to pick one.

After completing the design analysis and defining controls, the likelihood of exceeding the acceptance criteria, the design confidence and the risk, can be defined. This completes the risk based design analysis for one component and the process can now be repeated for all other components. The process can be mapped in a table, such as the one presented as Figure 3. 


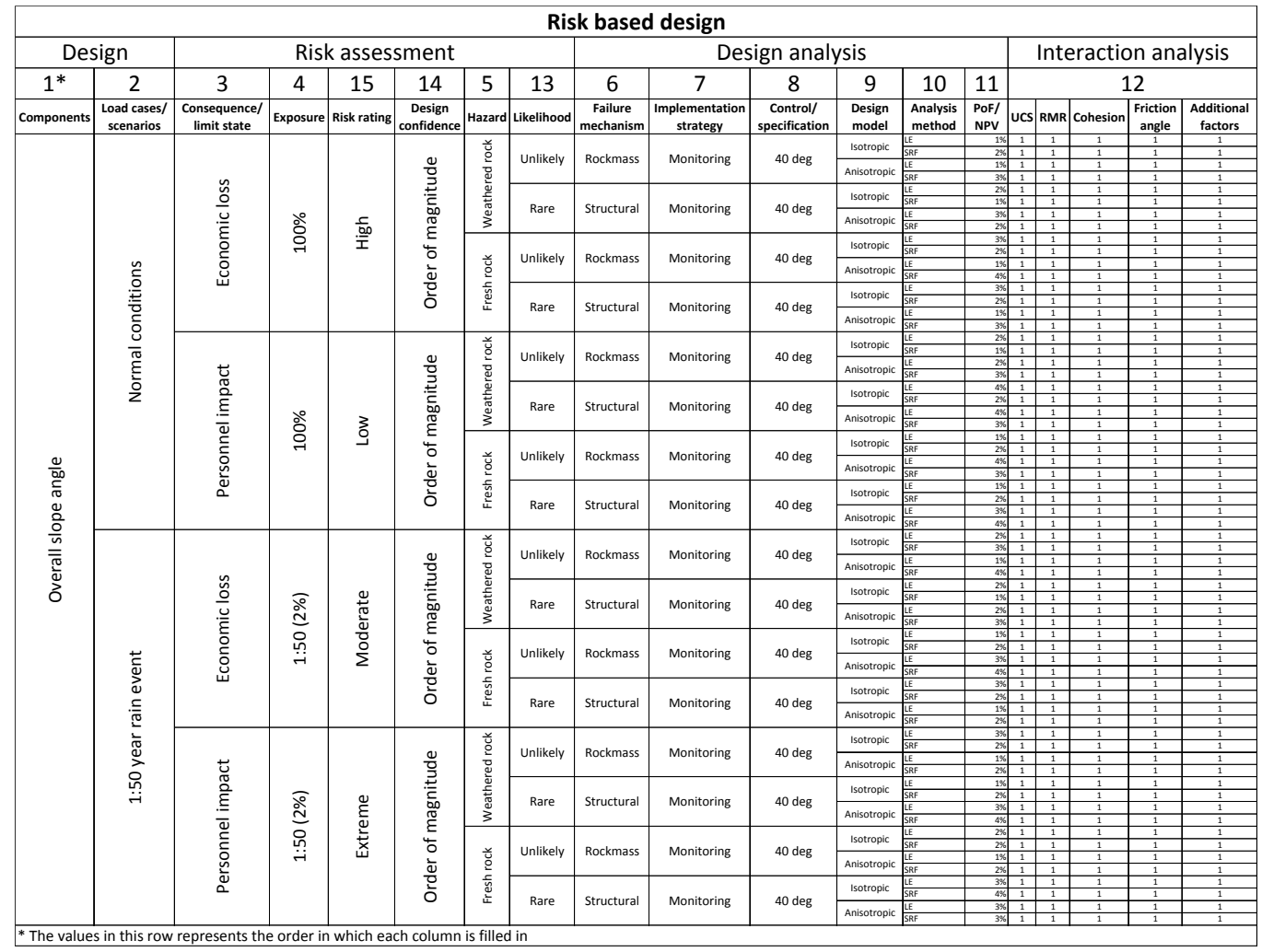

Figure 3 Design evaluation tool for open pits

Up to this point no mention has been made about the geology or engineering geology, however, it is clear from the information required that the geology and engineering geology is essential in providing the information required for the design. The site investigation is, therefore, an integral part of the design but, importantly, it is not the design itself. A site investigation on its own cannot substitute for a design and, conversely, a design cannot be completed without a site investigation. For a good design, a good site investigation and a good design process is required.

\subsection{Conclusion}

Based on the discussion so far it is proposed that design requires three types of information: strategic information, design analysis and site investigation. Strategic information is required to set goals for a design and is also the opportunity for a design project manager or director to control the outcome of a design. Design analysis is the result of the analysis carried out based on the design, and site investigation is the geological and scientific analysis of the terrain in which the design is to be constructed.

\section{Design evaluation tool defined}

The previous section defined, by way of an example, how a design has a natural flow of information and how this flow can be used to define a design evaluation tool. This section presents the strategic information required for design as well as the design evaluation tool. The strategic information required before planning a design analysis is presented first, followed by the design evaluation tool. The site investigation geology summary tool, or the 'site investigation tool' is presented in Section 5. This section makes reference to the word 'design' to denote the design and the word 'prototype' to denote the actual open pit. This nomenclature is necessary to ensure clarity in defining the design attributes. 


\subsection{Strategic information required for design}

A significant amount of information is needed before planning a design analysis. Much of this information is needed before writing a request for a proposal document or a proposal. It is suggested that the planning of a new design starts by collecting and documenting the following:

- Design objectives: this is recommended by Bieniawski (1992) and forms the basis of the rest of the design.

- Functional requirements of the prototype: again this is recommended by Bieniawski (1992) and will be needed when selecting the performance objectives.

- Performance objectives: these are the metrics used to define prototype failure. For open pits, these are typically in terms of Factor of Safety or Probability of Failure but could also be in terms of displacement or any other criteria. It must be noted that, for the purpose of this paper, the performance objectives and acceptance criteria are similar but not the same, even though the units of measurement could be the same. The performance objectives are specified by an asset owner or, in some cases, a governmental organisation. An example would be published values of acceptable Factor of Safety or Probability of Failure. The acceptance criteria are model dependant and are selected by the designer to test whether a model meets the performance objectives.

- Design constraints: they naturally contain a statement of the resources available for design but also contain practical information, such as: whether the crest is to be kept constant while varying the toe position, or keeping the toe constant and moving the crest in order to change the overall slope angle. There may even be other constraints, such as mine operators specifying a minimum berm width or ramp widths. In short, these are the constraints the designer has to work within and listing them early in a design will save lots of wasted time later.

- Prototype constraints: the prototype will have different constraints from the design, such as surface infrastructure, minimum achieved berms as per asset owner's instruction etc. These are the constraints the open pit has to adhere to.

\subsection{Design evaluation tool}

In the previous section the strategic information required before planning a design was presented. This section presents the risk based design evaluation process as a tool for general use and proposes that the table, presented as Figure 4, could be used to plan a slope design evaluation, from both a mine owner and designer's perspective, to communicate how a slope design is to be evaluated, or was evaluated, and also to review a slope design. The advantage offered by such a large table is that it provides an easy to view and understand perspective of a design evaluation. The inputs required in the table are explained and the table is represented for a general slope stability case. In each case, the input for a cell in a table can be: text explaining the entry, a reference to a report section providing more detail, a number (if appropriate), or a rating based on a predefined rating scheme. When presenting such a table, colour coding could also be used to simplify interpretation. 


\begin{tabular}{|c|c|c|c|c|c|c|c|c|c|c|c|c|c|c|c|c|c|c|}
\hline \multicolumn{19}{|c|}{ Risk based design } \\
\hline \multicolumn{2}{|c|}{ Design } & \multicolumn{6}{|c|}{ Risk assessment } & \multicolumn{6}{|c|}{ Design analysis } & \multirow{2}{*}{\multicolumn{5}{|c|}{$\frac{\text { Interaction analysis }}{12}$}} \\
\hline $1 *$ & 2 & 3 & 4 & 15 & 14 & 5 & 13 & 6 & 7 & 8 & 9 & 10 & 11 & & & & & \\
\hline Components & $\begin{array}{c}\text { Load cases/ } \\
\text { scenarios } \\
\end{array}$ & $\begin{array}{c}\begin{array}{c}\text { Consequence/ } \\
\text { limit state }\end{array} \\
\end{array}$ & Exposure & Risk rating & \begin{tabular}{|c|}
$\begin{array}{c}\text { Design } \\
\text { confidence }\end{array}$ \\
\end{tabular} & Hazard & Likelihood & \begin{tabular}{c|c}
$\begin{array}{c}\text { Failure } \\
\text { mechanism }\end{array}$ \\
\end{tabular} & \begin{tabular}{|c}
$\begin{array}{c}\text { Implementation } \\
\text { strategy }\end{array}$ \\
\end{tabular} & $\begin{array}{c}\text { Control/ } \\
\text { specification }\end{array}$ & $\begin{array}{l}\text { Design } \\
\text { model }\end{array}$ & $\begin{array}{l}\text { Analysis } \\
\text { method }\end{array}$ & \begin{tabular}{|l|} 
PoF/ \\
NPV \\
\end{tabular} & ucs & RMR & Cohesion & \begin{tabular}{|c|}
$\begin{array}{c}\text { Friction } \\
\text { angle }\end{array}$ \\
\end{tabular} & \begin{tabular}{|c|}
$\begin{array}{c}\text { Additional } \\
\text { factors }\end{array}$ \\
\end{tabular} \\
\hline \multirow{40}{*}{ 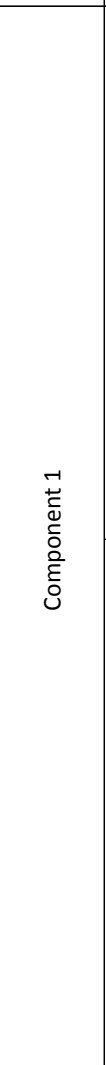 } & \multirow{20}{*}{ 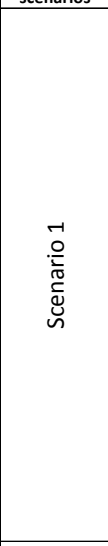 } & \multirow{10}{*}{ 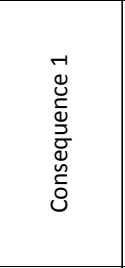 } & \multirow{10}{*}{ 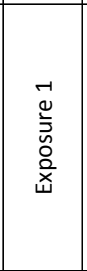 } & \multirow{10}{*}{$\frac{\vec{r}}{\frac{w}{x}}$} & \multirow{10}{*}{ 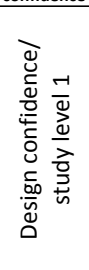 } & \multirow{5}{*}{ 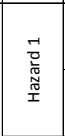 } & \multirow{2}{*}{$\begin{array}{c}\text { Likelihood } \\
\text { FM1 }\end{array}$} & \multirow{2}{*}{\begin{tabular}{|c|} 
Failure \\
Mechanism \\
1
\end{tabular}} & \multirow{2}{*}{\begin{tabular}{|c|}
$\begin{array}{c}\text { Implementation } \\
\text { strategy }\end{array}$ \\
\end{tabular}} & \multirow[b]{2}{*}{ Control Set 1} & DM1 & $\frac{A M 1}{A M 2}$ & \begin{tabular}{|l|l} 
Pof 1 \\
PoF 2
\end{tabular} & $\frac{1}{1}$ & $\frac{1}{1}$ & $\frac{1}{1}$ & \begin{tabular}{|l|} 
aingit \\
1 \\
1
\end{tabular} & \begin{tabular}{|l|l}
1 \\
1
\end{tabular} \\
\hline & & & & & & & & & & & DM2 & $\frac{A M 3}{A M 4}$ & \begin{tabular}{|l} 
POF 3 \\
POF 4
\end{tabular} & $\frac{1}{1}$ & $\frac{1}{1}$ & $\frac{1}{1}$ & $\frac{1}{1}$ & $\frac{1}{1}$ \\
\hline & & & & & & & \multirow{3}{*}{$\begin{array}{l}\text { Likelihood } \\
\text { FM2 }\end{array}$} & \multirow{3}{*}{$\begin{array}{c}\text { Failure } \\
\text { Mechanism }\end{array}$} & & & DM3 & $\begin{array}{l}\text { AMM } \\
\operatorname{Am} 5 \\
\end{array}$ & $\begin{array}{l}\text { port } \\
\text { Pof } 5 \\
\end{array}$ & $\frac{1}{1}$ & $\frac{1}{1}$ & $\frac{1}{1}$ & $\frac{1}{1}$ & $\frac{1}{1}$ \\
\hline & & & & & & & & & $\begin{array}{l}\text { Implementation } \\
\text { strategy }\end{array}$ & Control Set 2 & Dims & \begin{tabular}{|l|} 
AM 6 \\
AM
\end{tabular} & $\begin{array}{l}\text { Pof } 6 \\
\text { Pof7 }\end{array}$ & $\frac{1}{1}$ & $\frac{1}{1}$ & $\frac{1}{1}$ & $\frac{1}{1}$ & $\frac{1}{1}$ \\
\hline & & & & & & & & & & & & AM 8 & PoF 8 & 1 & 1 & 1 & 1 & 1 \\
\hline & & & & & & & Likelihood & \begin{tabular}{|c|} 
Failure \\
Mechanism
\end{tabular} & Implementation & Control Set 3 & DM5 & $\frac{\mathrm{AM} 9}{\mathrm{AM} 10}$ & 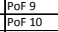 & $\frac{1}{1}$ & $\frac{1}{1}$ & $\frac{1}{1}$ & $\frac{1}{1}$ & $\frac{1}{1}$ \\
\hline & & & & & & 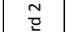 & FM3 & & strategy & Control Set 3 & DM6 & $\frac{A M 11}{A M 12}$ & $\begin{array}{l}\text { PoF 11 } \\
\text { PoF 12 }\end{array}$ & \begin{tabular}{|l}
1 \\
1
\end{tabular} & $\frac{1}{1}$ & $\frac{1}{1}$ & $\frac{1}{1}$ & $\frac{1}{1}$ \\
\hline & & & & & & 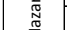 & & Failure & & & DM7 & AM 13 & PoF 13 & 1 & 1 & 1 & 1 & $\frac{1}{1}$ \\
\hline & & & & & & & $\begin{array}{c}\text { Likellhood } \\
\text { FM4 }\end{array}$ & Mechanism & $\begin{array}{l}\text { Implementation } \\
\text { strategy }\end{array}$ & Control Set 4 & PMe & $\mid \begin{array}{l}\text { AM M 1 } 15 \\
\text { A } 15\end{array}$ & \begin{tabular}{|l} 
Pof 144 \\
Pof 15
\end{tabular} & \begin{tabular}{|l}
1 \\
1 \\
\end{tabular} & $\frac{1}{1}$ & $\frac{1}{1}$ & $\frac{1}{1}$ & $\frac{1}{1}$ \\
\hline & & & & & & & & & & & DIM8 & \begin{tabular}{|l|} 
AM 16 \\
AM 17
\end{tabular} & \begin{tabular}{|l|l|} 
PoF 16 \\
POF F
\end{tabular} & \begin{tabular}{|l|l|}
1 \\
1
\end{tabular} & $\frac{1}{1}$ & $\frac{1}{1}$ & $\frac{1}{1}$ & $\frac{1}{1}$ \\
\hline & & & & & & & Likelihood & \begin{tabular}{|c|} 
Fallure \\
Mechanism
\end{tabular} & Implementation & Control Set 5 & DM9 & AM 18 & PoF 18 & \begin{tabular}{|l|}
1 \\
\end{tabular} & 1 & 1 & 1 & 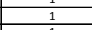 \\
\hline & & & & & & 인 & & 5 & & Somitrol set & DM10 & $\frac{\mathrm{AM} 19}{\mathrm{AM} 20}$ & 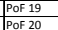 & \begin{tabular}{|l|l|}
1 \\
1
\end{tabular} & $\frac{1}{1}$ & $\frac{1}{1}$ & $\frac{1}{1}$ & $\frac{1}{1}$ \\
\hline & & 8 & & & $\stackrel{c}{2}$ & $\underset{\pi}{\pi}$ & & Failure & & & DM11 & AM 211 & PoF 21 & 1 & 1 & 1 & 1 & 1 \\
\hline & & $\frac{1}{d}$ & $\cong$ & $\sim$ & 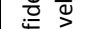 & & FM6 & Mechanism & strategy & Control Set 6 & DM12 & $\frac{\mathrm{AMM} 22}{\mathrm{AM} 23}$ & 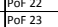 & $\frac{1}{1}$ & $\frac{1}{1}$ & $\frac{1}{1}$ & $\frac{1}{1}$ & 1 \\
\hline & & 岂 & ज & 畜 & 흥 & & & & & & DMII & $\operatorname{AM~} 24$ & \begin{tabular}{|l|l|} 
PoF 24 \\
\end{tabular} & 1 & 1 & 1 & 1 & 1 \\
\hline & & $\underset{凶}{ }$ & 욤 & $\frac{\pi}{x}$ & iे & & Likelihood & \begin{tabular}{|l|} 
Failure \\
\end{tabular} & Implementation & Control $\mathrm{Cot} 7$ & DM13 & $\frac{\mathrm{AM} 25}{\mathrm{AM} 26}$ & $\frac{\mid \mathrm{PPF} 25}{\mathrm{PO} 26}$ & \begin{tabular}{|l|} 
\\
1
\end{tabular} & $\frac{1}{1}$ & $\frac{1}{1}$ & $\frac{1}{1}$ & $\frac{1}{1}$ \\
\hline & & $\tilde{c}$ & 爻 & & 品 & $\frac{0}{2}$ & FM7 & Mechanism & strategy & Control Set 7 & DM14 & \begin{tabular}{|l|l|} 
AM 27 \\
$A M 28$
\end{tabular} & \begin{tabular}{|l|l|} 
Pof 27 \\
Po 228
\end{tabular} & \begin{tabular}{|l}
1 \\
\end{tabular} & 1 & $\frac{1}{1}$ & 1 & 1 \\
\hline & & & & & $\bar{y}^{\infty}$ & 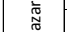 & & \begin{tabular}{|l|l|} 
Failure \\
\end{tabular} & & & DM15 & \begin{tabular}{|l}
$\operatorname{AM} 28$ \\
$\operatorname{AM} 29$ \\
$\ln 23$
\end{tabular} & \begin{tabular}{|l} 
PoF 28 \\
PoF 29 \\
$P O 29$
\end{tabular} & \begin{tabular}{|l|}
1 \\
1 \\
\end{tabular} & $\frac{1}{1}$ & $\frac{1}{1}$ & $\frac{1}{1}$ & 1 \\
\hline & & & & & & & Likellhood & Mechanism & Implementation & Control Set 8 & & AM 30 & PoF 30 & 1 & 1 & 1 & 1 & 1 \\
\hline & & & & & & & & 8 & & & DM16 & $\frac{\mathrm{AMM} 11}{\mathrm{AM} 32}$ & 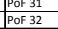 & $\frac{1}{1}$ & $\frac{1}{1}$ & $\frac{1}{1}$ & $\frac{1}{1}$ & $\frac{1}{1}$ \\
\hline & & & & & & & Likelihood & Failure & Implementation & & DM17 & $\operatorname{Am~} 33$ & Poo 33 & 1 & 1 & 1 & 1 & 1 \\
\hline & & & & & & & FM9 & Mechanism & strategy & Control Set 9 & DM18 & $\begin{array}{ll}\mathrm{AMM} 35 \\
\mathrm{AM}\end{array}$ & PoF 35 & \begin{tabular}{|l|}
1 \\
\end{tabular} & $\frac{1}{1}$ & 1 & 1 & 1 \\
\hline & & m & & & $\stackrel{\subseteq}{\subseteq} m$ & 胥 & & & & & & $\mid \frac{\mathrm{AM} 36}{\mathrm{AM} 37}$ & \begin{tabular}{|l|l|} 
POF 36 \\
PoF 37
\end{tabular} & \begin{tabular}{|l|} 
\\
1
\end{tabular} & $\frac{1}{1}$ & $\frac{1}{1}$ & $\frac{1}{1}$ & $\frac{1}{1}$ \\
\hline & & $\breve{\Xi}$ & $m_{0}^{m}$ & & $\frac{\Phi}{0} \bar{\Phi}$ & & Likelihood & Mechanism & Implementation & Control Set 10 & DM19 & AM 38 & PoF 38 & 1 & 1 & 1 & 1 & 1 \\
\hline & & $\bar{\Xi}$ & $\frac{5}{3}$ & $\underset{m}{m}$ & 妾 d & & FM10 & & strategy & Control set 10 & DM20 & $\frac{A M 39}{A M 40}$ & \begin{tabular}{|l|l|} 
PoF 39 \\
POF 40
\end{tabular} & $\begin{array}{l}1 \\
1\end{array}$ & $\begin{array}{ll}1 \\
1\end{array}$ & $\frac{1}{1}$ & $\frac{1}{1}$ & $\frac{1}{1}$ \\
\hline & & $\vec{\sigma}$ & 气̆ & $\frac{\bar{m}}{x}$ & 0 & & likelihond & Failure & & & DM21 & AM 41 & PoF 41 & \begin{tabular}{|l|l|}
1 \\
\end{tabular} & 1 & 1 & 1 & 1 \\
\hline & & $\breve{\omega}$ & $\frac{a}{x}$ & & 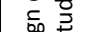 & 0 & $\begin{array}{c}\text { Theilnood } \\
\text { FM11 }\end{array}$ & Mechanism & $\begin{array}{l}\text { Implementation } \\
\text { strategy }\end{array}$ & Control Set 11 & ב & & 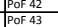 & \begin{tabular}{|l|}
1 \\
1
\end{tabular} & $\frac{1}{1}$ & $\frac{1}{1}$ & $\frac{1}{1}$ & 1 \\
\hline & & & & & $\bar{\omega}$ & $\frac{0}{5}$ & & 11 & & & DM22 & AM 44 & \begin{tabular}{|l|l|} 
PoF 44 \\
Po 44
\end{tabular} & 1 & 1 & 1 & 1 & 1 \\
\hline & & & & & & 筀 & Likelihood & Failure & Implementation & Controlset 12 & DM23 & $\frac{\mathrm{AM} 45}{\mathrm{AM} 46}$ & $\mid \frac{\mid P \text { PoF } 45}{\text { PoF } 46}$ & \begin{tabular}{|l|}
1 \\
1
\end{tabular} & $\frac{1}{1}$ & $\frac{1}{1}$ & $\frac{1}{1}$ & $\frac{1}{1}$ \\
\hline & 은 & & & & & & FM12 & & strategy & Control Set 12 & DM24 & \begin{tabular}{|l|l|}
$A M 47$ \\
$A M 48$
\end{tabular} & \begin{tabular}{|l|} 
PoF 47 \\
POF 48
\end{tabular} & \begin{tabular}{|l|l}
1 \\
1
\end{tabular} & 1 & $\frac{1}{1}$ & 1 & 1 \\
\hline & $\stackrel{0}{\frac{1}{C}}$ & & & & & & & Failure & & & DM25 & AM 49 & \begin{tabular}{|l|l|} 
PoF 499 \\
\end{tabular} & \begin{tabular}{|l|l|}
1 \\
\end{tabular} & 1 & 1 & 1 & 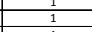 \\
\hline & 岕 & & & & & $\hat{7}$ & $\begin{array}{c}\text { Theilnood } \\
\text { FM13 }\end{array}$ & Mechanism & $\begin{array}{l}\text { Implemtation } \\
\text { strategy }\end{array}$ & Control Set 13 & DM26 & $\begin{array}{l}\text { AM } 50 \\
A M 51 \\
\end{array}$ & \begin{tabular}{|l} 
PoF 50 \\
PoF 51
\end{tabular} & \begin{tabular}{|l|}
1 \\
1
\end{tabular} & $\begin{array}{l}1 \\
1 \\
\end{array}$ & $\frac{1}{1}$ & $\frac{1}{1}$ & 1 \\
\hline & & & & & $\breve{c} \theta$ & 해 & & & & & & $\begin{array}{l}A M 52 \\
A M 53\end{array}$ & \begin{tabular}{|l|l|} 
POF 52 \\
POF 53
\end{tabular} & 1 & 1 & 1 & 1 & 1 \\
\hline & & $\stackrel{\Xi}{(}$ & & & $\overline{0} \frac{\overline{0}}{0}$ & $\frac{\pi}{I}$ & Likelihood & Failure & Implementation & Control Set 14 & DM27 & $\frac{\mathrm{AMM} 33}{\mathrm{AM} 54}$ & \begin{tabular}{|l|l|} 
PoF 53 \\
PoF 54
\end{tabular} & \begin{tabular}{|l|l|} 
\\
\end{tabular} & $\frac{1}{1}$ & $\frac{1}{1}$ & $\frac{1}{1}$ & $\frac{1}{1}$ \\
\hline & & 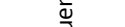 & ङ & $\stackrel{8}{2}$ & 妾 & & FM14 & 14 & strategy & Cominos 35 & DM28 & $\begin{array}{ll}A M 55 \\
A M 56\end{array}$ & \begin{tabular}{|l} 
POF 55 \\
POF 56
\end{tabular} & 1 & 1 & 1 & 1 & 1 \\
\hline & & $\vec{\sigma}$ & ڤ̆ & $\frac{\bar{m}}{x}$ & $\bar{y} \bar{x}$ & & & Failure & & & DM29 & $A M$ & Pof 57 & 1 & 1 & 1 & 1 & 1 \\
\hline & & $\check{c}$ & $\frac{2}{x}$ & & $\therefore 5$ & $\infty$ & FM15 & Mechanism & strategy & Control Set 15 & DM30 & An & Por & \begin{tabular}{|l|l|} 
\\
\end{tabular} & $\frac{1}{1}$ & $\frac{1}{1}$ & 1 & $\frac{1}{1}$ \\
\hline & & & & & w & $\frac{1}{5}$ & & 15 & & & onvisu & AM 60 & PoF 60 & 1 & 1 & 1 & 1 & 1 \\
\hline & & & & & & 疍 & Likelihood & Failure & Implementation & C & DM31 & $\frac{A M}{A M}$ & \begin{tabular}{|l|l|} 
Pof 61 \\
Pof 62
\end{tabular} & \begin{tabular}{|l|}
1 \\
1
\end{tabular} & $\frac{1}{1}$ & $\frac{1}{1}$ & $\frac{1}{1}$ & 1 \\
\hline & & & & & & & 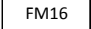 & Mechanism & strategy & Control set 16 & DM32 & $\frac{A M 63}{A M{ }^{2}}$ & \begin{tabular}{|l|l|} 
PoF 63 \\
POF 64
\end{tabular} & \begin{tabular}{|l|l|}
1 \\
1
\end{tabular} & 1 & 1 & 1 & 1 \\
\hline
\end{tabular}

Figure 4 Design evaluation tool

The first column in the design evaluation tool is for the components of the design. Each component will have a line dedicated to its evaluation. If components share the same evaluation methodologies and risk it may be possible to group them into one line. It is suggested that, as a minimum, each design sector will have the components: overall slope angle, inter-ramp or bench stack slope angle for each inter-ramp slope and bench stack, batter face angle, berm width, geotechnical or catch berm width and ramp width. In many cases it may be possible to merge some of these items, as the analysis will be the same. For instance, the analysis for the ramp width and catch berm width may overlap.

The second column is for the design scenario or load case. Typically, some of these may be specified by the mine operator and could be driven by insurance requirements, financing requirements, or special local conditions that require specific evaluation. Examples of such items are nearby infrastructure, such as roads, lakes, crushers, control centres, bore fields, environmentally sensitive areas, heritage areas, and natural hazards, such as large rain events, earthquakes, volcanic activity, as well as geological and mining factors, such as adverse faults or geological information, poor blasting or mining non-conformance.

There may also be alternative mine planning scenarios that need to be evaluated. In structural engineering many of these scenarios are defined in detail by a document called a 'loading code'. In Australia the loading code is Australian Standard AS 1170 but this has limited application to open pit design. In open pit design there is no universal loading code and designers are left to their own devices. It is prudent in all cases, when commissioning a design, to specify which scenarios are to be analysed and when carrying out or quoting a pit slope design to clarify which scenarios are expected. This will prevent much heartache later.

The third column is for documenting the consequences of a particular scenario for a given component. It is important to be specific about the consequence as it will help define the hazards, failure mechanisms and 
the level of rigour required for the analysis. For instance, do not record 'slope failure', instead record 'slope instability has the potential sterilise $400 \mathrm{kT}$ of ore'. Another example is 'displacement at the slope crest has the potential to cause distortion of the in-pit crusher foundations, which will render the crusher inoperable'.

The fourth column is for the exposure of the component to a given scenario. Some scenarios are active most of the time, such as normal operating conditions. Others are active for short periods of time, such as extreme weather events or earthquakes and other natural disasters. There are also scenarios that may be present most of the time but have not been detected yet, such as an adverse fault or highly weathered zone. In such cases, a monitoring or exploration programme can be specified to detect the scenario. The designer, with involvement from the asset owner, can decide to include such a scenario in the analysis but may then use the exposure column to record the degree of confidence for that scenario to exist. Lastly, some scenarios can be man-made, such as poor mining conformance to design, or poor groundwater management. The exposure column will record the confidence in the operations team in such cases. Exposure is also an important factor in determining appropriate acceptance criteria. Structural engineering loading codes often allow lower acceptance criteria for short-term events than longer term operating conditions. This process can also be used to demonstrate to mine owners how the performance of site based depressurisation crews or the mine design performance can influence analysis acceptance criteria.

The fifth column is to report the risk rating and will only be filled in once the design analysis supporting that scenario is complete. Depending on the level of rigour applied to the analysis using the required study level as a guide, and whether acceptance criteria is based on probability or any of the other acceptance criteria such as displacement or Factor of Safety, the risk rating could be a probability of a scenario resulting in design failure, or it could be a subjective risk classification such as the commonly used risk matrices.

The sixth column represents design confidence. The design confidence could be recorded in terms of mining study levels such as conceptual, order of magnitude, prefeasibility, feasibility, bankable feasibility or implementation. Should other classifications be more appropriate, these could be used. Before embarking on a design there is often a required study level and this column could be populated with the required study levels, however, in practice one often finds some data deficiency or other limitation. As a result, designs do not always live up to the required study level. This column provides the designer the opportunity to declare, for each hazard, what the achieved study level is. It also provides the reviewer a high level map of the entire design, indicating where the desired study level has not been achieved.

The seventh column provides a description of the hazard. In this context, the standard definition of a hazard applies: 'a hazard is anything with the potential to cause harm'. The level of detail required should be sufficient to define the hazard but not the failure mechanisms. For instance, a hazard could be a given dolerite dyke or swarm of dykes, a known fault or other structural feature, a known water source, a weathered zone or any other object or feature that has the potential to cause harm for a given scenario. For scenarios testing hypothetical conditions, details of the hypothetical conditions will be presented as hazards.

The eighth column presents the likelihood of a given hazard causing harm. This column is only populated after completing the design analysis, as the results of the design analysis are required. Similar to the risk rating column, the likelihood column could be either a probability value or a rating such as rare, unlikely, likely or almost certain, as defined using any of the available risk assessment matrices. The value recorded in the likelihood column will be a representation of the design analysis results for a given hazard. If using probabilistic design analysis, the likelihood will be the sum of probabilities as reported in column 14 but when using a rating system with Factor of Safety, displacement or other acceptance criteria, an alternative representation system could be used, such as always reporting the highest risk rating.

The ninth column presents the failure mechanism. The failure mechanism is the mechanics required for a hazard to activate. For instance, loose rocks can be a hazard but many mechanisms may trigger them to loosen and fall such as erosion of core stones, blast vibrations on highly fractured rock etc. It is this underlying mechanism that is to be recorded here. The detail required should be sufficient to explain the choice of design model and analysis method. 
The 10th column presents the implementation strategy such as the Observational Method, the New Austrian Tunneling Method, the Norwegian Tunneling Method or any other specific strategy. The description here could refer to a reference in the report with more detail, but should at least specify whether the design assumes monitoring and additional data collection during or after construction. Being specific here will serve as a reminder to the designer to think about implementation and will communicate to the reviewer and implementer that, while the data is not complete, further work is to be planned.

The 11th column presents the controls used for a given set of analysis. Due to space requirements all controls might not be recorded here but a reference to a control set number could be used instead with more detail recorded elsewhere in a report. If multiple sets of controls are tested, a different line could be created for each test. Naturally, only the set selected for the design will have their analysis results included in the likelihood column. It could be argued that different sets of controls could represent different scenarios, however, the author considered that it would be more appropriate to provide a separate line as it will reduce the amount of duplication in the table.

The 12th column presents a short note on the design model used. It makes sense to include a reference to where the model details are presented but it is also important to record the type of model for instance: continuum, particulate (consisting of particles), fracture network, anisotropic, ubiquitous joints, modelled as rock, modelled as soil, elasto-plastic with strain softening etc. to name but a few.

The 13th column presents the analysis method. This column will contain software names or references to equations used for the analysis. If proprietary software was used, this will be recorded in this column. As it is possible to model the same model type in more than one software package or equation, high consequence and high risk scenarios could be modelled using multiple methods to ensure reliable analysis results are obtained.

The 14th column presents the results of each analysis using the input parameters selected as representative for the design. The results could be either probabilities, Factor of Safety displacements, or any other type as required. For evaluating controls with financial outcomes, the Net Present Value (NPV) could also be used.

Finally, all additional columns, to the right, represent factors that could influence the analysis results. One factor per column. These factors could include geological factors, such as bedding plane dip and degree of weathering, geotechnical factors, such as geological strength index or rock mass rating, soil or rock mechanics factors, such as cohesion and friction angle, analysis method factors, such as finite element size or distance to external boundary, or finally software package factors, such as detailed settings that could influence the design outcome. The factor being tested is used as a column heading and a measure of sensitivity, to a given factor, is recorded in the appropriate line. To obtain such a measure, a sensitivity analysis will have to be carried out. The measure used could be anything appropriate but will have to correspond to the risk of the scenario and the design confidence required. For example, for a low level study, a rating system could be devised stating simply how important a factor is to the analysis with wording such as 'very important', 'essential' or 'not important'. Alternatively, the ratio of the percentage change in the given factor to the percentage change in the analysis result could be provided. Documenting the sensitivity results in such a way will provide a full design plan that could be used to delegate a design or as part of a tender document. It will also make it very clear to a reviewer or end user how well a design considered the important factors and whether a design could be based on a limited understanding of the problem. This part of the figure is similar to that proposed by Hudson and Harrison (1997) but contains less information. For this reason, it may still be advisable to complete a Harrison table.

In summary, this section presented the design evaluation tool for open pits, however, the tool could be applied to evaluate any geotechnical design. Understandably many readers, especially more experienced readers, will feel that they are already following this process. This stems from the fact that this tool does not represent a different way of evaluating designs, but merely maps out the design evaluation process. The practical use of the design evaluation tool is for project managers to specify the design evaluation process expected, for design principals to plan and delegate design evaluation to designers and, as a quality assurance aid, for designers to record details of their work as a summary and to track progress, and for reviewers and 
implementers to see a complete map of the design evaluation in order to understand the design better and be able to make judgements more correctly and with less effort.

\section{$5 \quad$ Site investigation tool}

The previous section developed and presented the design evaluation tool. At this point the reader with some geological background is likely to feel that the design evaluation tool lacks geological information. This is because a two-dimensional table is not sufficient to allow inclusion of the site investigation. The site investigation is mapped in a site investigation tool presented in this section. It is envisaged that the site investigation tool and the design evaluation tool be populated in parallel, although there are likely to be several iterations before either can be finalised.

In order to determine how the site investigation tool and design evaluation tool interact, the design evaluation tool (Figure 4) is considered from left to right. The first column labelled components, usually does not require geological information. The second column labelled load cases, may in some cases require geological input such as specification of a rogue fault as yet unknown or an alternative geological interpretation that may be less favourable. The next column requiring geological or geotechnical information is the hazard column. For slope design, most hazards will be geological in nature and one of the primary functions of a site investigation is to identify possible hazards. The next column to require geotechnical information is the failure mechanism column. Geotechnical and geological analysis and experience will be required to identify possible failure mechanisms. A good aid to identifying hazards is stereonet analysis, although on its own, stereonet analysis is not sufficient. The design model column will require all the geological and geotechnical characterisation data as input. One or more geological and geotechnical models may be required as well as the field and laboratory testing required to provide inputs for the analysis models. In summary, the purpose of a site investigation is to provide input into alternative scenarios that may be required, identification of hazards, identification of failure mechanisms, model definition and parameter definition.

To provide these inputs and identify the hazards, it is necessary to critically evaluate and summarise the geological and geotechnical factors that could provide inputs for the design evaluation tool (Figure 4). Such a summary begins by considering all the important geological factors that are required to be collected by International Society for Rock Mechanics. Summarising all of the data in one place allows the hazards to be spotted and could look like Figure 5. Given the complex nature of geology it is not realistic to be able to provide all important parameters in a single table. Figure 5 must, therefore, be seen as a starting point that may require the addition of columns depending on the situation. 


\begin{tabular}{|c|c|c|c|c|c|c|c|c|c|c|c|c|c|c|c|}
\hline \multicolumn{16}{|c|}{ Engineering Geology } \\
\hline \multicolumn{7}{|c|}{ Geology } & \multicolumn{4}{|c|}{$\begin{array}{c}\text { Structural } \\
\text { Geology }\end{array}$} & \multicolumn{3}{|c|}{$\begin{array}{c}\text { Geotechnical } \\
\text { Geology }\end{array}$} & \multicolumn{2}{|c|}{$\begin{array}{c}\text { Geological Risk } \\
\text { Assessment }\end{array}$} \\
\hline 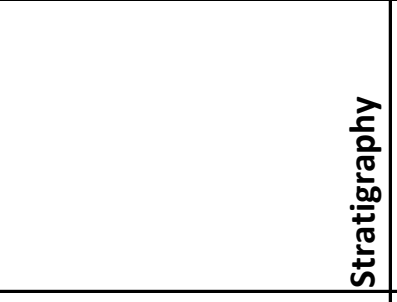 & 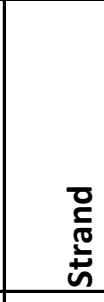 & 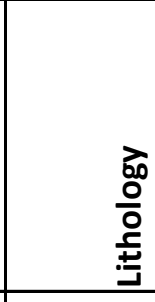 & 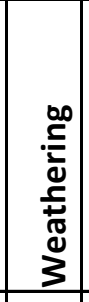 &  & 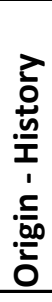 & 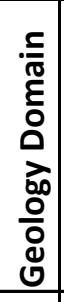 & 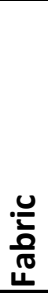 & 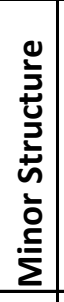 & 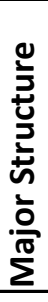 & 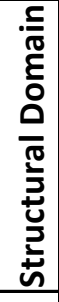 & $\begin{array}{l}\tilde{y} \\
\text { } \\
\frac{0}{0} \\
\frac{T}{1} \\
\end{array}$ & 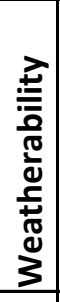 & 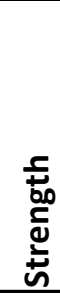 &  & 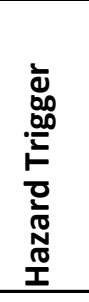 \\
\hline \multirow{15}{*}{ Blue Mountain Formation } & \multirow{7}{*}{ Upper } & \multirow{4}{*}{ Sediment } & HW & & & & & & & & & & & & \\
\hline & & & & & & & & & & & & & & & \\
\hline & & & MWL & & & & & & & & & & & & \\
\hline & & & & & & & & & & & & & & & \\
\hline & & \multirow{3}{*}{ Granite } & HW & & & & & & & & & & & & \\
\hline & & & & & & & & & & & & & & & \\
\hline & & & MW & & & & & & & & & & & & \\
\hline & \multirow{8}{*}{ Lower } & & & & & & & & & & & & & & \\
\hline & & \multirow{3}{*}{ Hornfels } & $\mathrm{HW}$ & & & & & & & & & & & & \\
\hline & & & & & & & & & & & & & & & \\
\hline & & & IMVF & & & & & & & & & & & & \\
\hline & & \multirow{5}{*}{ Schist } & & & & & & & & & & & & & \\
\hline & & & $\mathrm{HW}$ & & & & & & & & & & & & \\
\hline & & & & & & & & & & & & & & & \\
\hline & & & $\mathrm{MW}$ & & & & & & & & & & & & \\
\hline & & & & & & & & & & & & & & & \\
\hline
\end{tabular}

Figure 5 Site investigation tool

\section{Conclusion}

In conclusion, it is unlikely that the debate over how to improve design practice will ever be complete. What is certain is that good design adds value. This paper presented an alternative point of view to approaching a design through the inclusion of the risk based design evaluation tool (Figure 4) and site investigation geology summary tool (Figure 5). It is hoped that the reader will use these tools for design and amend and update them as required. But more importantly, it is hoped that the topic of design will remain a point of discussion between geotechnical engineers old and young to ensure that the truly important decisions are not left to chance.

\section{References}

ABET (Accreditation Board for Engineering and Technology) 1987, Fifth Annual Report, Accreditation Board for Engineering and Technology, Washington DC.

Ang, AH-S \& Tang, WH 1975, Probability Concepts in Engineering Planning and Design: Volume I-Basic Principles, John Wiley \& Sons, New York.

Ang, AH-S \& Tang, WH 1990, Probability Concepts in Engineering Planning and Design: Volume II - Decision, Risk and Reliability, John Wiley \& Sons, New York.

Ang, AH-S \& Tang, WH 2007, Probability Concepts in Engineering, 2nd ed, John Wiley \& Sons, New Jersey.

AS/NZS 4360 1999, AS/NZS 4360:1999 Risk Management, Standards Australia.

Baecher, GB \& Christian, JT 2003, Reliability and Statistics in Geotechnical Engineering, John Wiley \& Sons, Chichester.

Bieniawski, Z 1984, 'The Design Process in Rock Engineering', Rock Mechanics and Rock Engineering, pp. 183-190.

Bieniawski, Z 1988, 'Towards a Creative Design Process', Rock Engineering Mining Engineering, pp. 1040-1044.

Bieniawski, Z 1992, Design Methodology in Rock Engineering, Balkema, Rotterdam.

Fenton, GA \& Griffiths, D 2008, Risk Assessment in Geotechnical Engineering, John Wiley \& Sons, New Jersey.

Harr, ME 1987, Reliability Based Design in Civil Engineering, Dover Publications Inc., New York.

Hudson, JA \& Harrison, JP 1997, Engineering Rock Mechanics: An Introduction to the Principles, Elsevier Science, Oxford. Mackenzie, W \& Cusworth, N 2007, The Use and Abuse of Feasibility Studies, Project Evaluation Conference, Melbourne. 
Read, J \& Stacey, P (eds) 2009, Guidelines for Open Pit Slope Design, CSIRO Publishing, Collingwood.

Stacey, P 2009, 'Fundamentals of Slope Design', in J Read \& P Stacey (eds), Guidelines for Open Pit Slope Design, CSIRO Publishing, Collingwood, pp. 1-14.

Stacey, T 2014, 'Design - a strategic issue', Australian Centre for Geomechanics Newsletter, December, pp. 1-4.

Vick, SJ 2002, Degrees of Belief: Subjective Probability and Engineering Judgement, American Society of Civil Engineers, Reston, VA. Wikipedia 2016, Open-pit Mining, viewed 12 May 2016, https://en.wikipedia.org/wiki/Open-pit_mining 